\title{
Interrelationship of linear dimensions as growth corollary of pama croaker Otolithoides pama in the Bay of Bengal
}

\author{
ZOARDER FARUQUE AHMED*, MST. KANIZ FATEMA, UMME HABIBA AZ \\ ZOHORA, MANSURA AKTER JOBA AND FERDOUS AHAMED ${ }^{1}$
}

Department of Fisheries Management, Bangladesh Agricultural University, Mymensingh 2202, Bangladesh

${ }^{1}$ Department of Fisheries Management, Patuakhali Science and Technology University, Patuakhali 8602

*Email: zoarder@bau.edu.bd

\begin{abstract}
Growth pattern of pama croaker Otolithoides pama population in the Bay of Bengal was determined as the corollary of relationships between standard length (SL) and total length (TL), the two most prevalently used linear dimensions of fin fish species. Monthly pama croaker samples were collected from the industrial fisheries in the Bay of Bengal. The length-length relationship was constructed algebraically in the form of $\mathrm{y}=\mathrm{a}+\mathrm{bx}$. Relationships between SL and TL for male, female and unsexed populations were separately established. Sex ratio between male and female did not deviate from the parity $\left(\chi^{2}\right.$ test; $\left.p>0.05\right)$. The SL and TL ranges of male were 7.2-22 cm and 9.5-28 cm respectively, and the SL and TL ranges of female were $6.8-20 \mathrm{~cm}$ and $8.4-25.7 \mathrm{~cm}$ respectively. Intercept and slope varied monthly in all length-length relationships regardless of gender categories. The generalized SL-TL relationships of male, female and unsexed populations were $\mathrm{TL}=1.214 \mathrm{SL}+0.761(\mathrm{R}=0.989), \mathrm{TL}=1.212 \mathrm{SL}-0.770(\mathrm{R}=0.990)$ and $\mathrm{TL}=1.203 \mathrm{SL}+0.904$ $(\mathrm{R}=0.987)$ respectively. The correlation coefficients of both monthly and generalized regression analyses of all sex types were very high $(R \geq 0.852)$ which explained that the relationships between the two length dimensions were strongly correlated. The growth corollary appeared both as isometric and allometric for monthly populations. Allometric growth was apparent in July, August and September in all gender types, while isometric growth was deduced in other months. This study would be useful for future research in order to make comparisons with the relevant aspects of $O$. pama population between years and locations in the Bay of Bengal.
\end{abstract}

Keywords: Otolithoides pama, Length-length relationship, Bay of Bengal

\section{Introduction}

The significance of length-length relationships in fisheries science has been well documented (Pauly 1993, Petrakis and Stergiou 1995, Binohlan and Pauly 2000, Binohlan et al. 2000, Froese and Pauly 2000, Froese 2006). Length-length relationships are important for comparative growth studies (Moutopoulos and Stergiou 2002), and are used as the corollary of growth pattern. Fish from birth undergo physiological process having isometric or allometric as a natural consequence over life cycle. Although length-length relationships are readily available for most European and North American freshwater and marine fishes (e.g. Petrakis and Stergiou 1995, Sinovcic et al. 2004), but information on length-length relationships are still scarce for most tropical and sub-tropical fish species (Martin-Smith 1996, Harrison 2001, Ecoutin et al. 2005). The length-length relationship has been applied for basic uses in order to make fish stocks assessment (Ricker 1968). In fish, size is generally more biologically relevant than age, mainly because several ecological and physiological factors are more size-dependent than agedependence. Consequently, length-length regressions have been used frequently to estimate unknown lengths from the established equations readily at later period because direct measurements of needful can be time-consuming in the field (Sinovcic et al. 2004). The pama croaker, Otolithoides pama (Hamilton 1822), Perciformes: Sciaenidae, locally known as laiza poa is a commercially important fish species, widespread in the Bay of Bengal, and commonly 
caught in every fishing point of coastal rivers and marine areas in Bangladesh. Present research attempted to provide baseline information for the growth pattern of $O$. pama as the corollary of length-length relationship analysis.

\section{Materials and Methods}

Study area and fish sample collection: Samples of $O$. pama were collected once a month over an entire calendar year from January to December from the industrial fisheries operated in the Bay of Bangle based in Chittagong. Fishers revealed that trawl net with fine meshed cod end were used to catch the fish. All specimens were preserved with small ice crystals in an insulated fish box to avoid decomposition of fish.

Recording of lengths: Linear dimension of fish as linear distance of body length which is measured by scale. To carry out present research two linear dimensions of standard length and total length were considered. Standard length was measured from the tip of the snout (mouth closed) to the last vertebrae, and total length from the tip of the snout to the end of caudal fin. Both lengths were taken to the nearest $\mathrm{cm}$ with the help of a measuring board. Data were input on the spreadsheet of the computer software, Microsoft Excel.

Gonad collection and sex determination: The body cavity of a fish was cut open carefully by scissors, and gonads were extracted with forceps carefully. Fishes were sexed as male and female observing the gonads with naked eye.

Estimation of length-length relationship: A linear relationship between standard length (SL) and total length (TL) was estimated using the equation: $\mathrm{TL}=a+b S L$ where ' $a$ ' and ' $b$ ' are constants as intercept and slope respectively. Estimates of ' $a$ ' and ' $b$ ', and their $95 \%$ confidence limits were computed statistically.

Growth corollary: Fish grow at the same rate in all linear dimensions, that means, increases in standard length and total length are proportional to each other. This pattern of growth is called isometric growth; otherwise it is termed as allometric. The value of intercept, 'a' in the $y=a+b x$ denoted growth corollary. The confidence interval for the population intercept of the length-length relationship equation reveals the growth pattern. In this study if the confidence limits at $95 \%$ confidence level of population intercept includes zero, then the growth was said to be isometric.

\section{Results}

Fish size: The investigation dealt with a total of 500 pama croaker individuals. Among them, 258 were male and 242 were female. The standard length and total length of male ranged from 2.4 to $8.2 \mathrm{~cm}$, and from 3.6 to $10.5 \mathrm{~cm}$ respectively. The standard length and total length of female measured from 5.7 to $9.0 \mathrm{~cm}$, and from 3.5 to $12.5 \mathrm{~cm}$ respectively (Table I). 


\section{Size relationships and growth pattern}

Male population: Relationships between standard length vs. total length of monthly samples showed variations in both constants ('a' and 'b') and correlation coefficients (R) of the linear equations. Results of the analyses are given in Table II.

Table I. Details for monthly samples of pama croaker $O$. pama population collected from the Bay of Bengal (Obs, observation; SL, standard length; TL, total length)

\begin{tabular}{lllllll}
\hline \multirow{2}{*}{ Month } & \multicolumn{3}{c}{ Male } & \multicolumn{2}{c}{ Female } \\
\cline { 2 - 7 } & Obs. & SL $(\mathrm{cm})$ & TL $(\mathrm{cm})$ & Obs. & SL $(\mathrm{cm})$ & TL $(\mathrm{cm})$ \\
\cline { 2 - 7 } January & 27 & $14-17.2$ & $17.7-22$ & 23 & $11.9-18.1$ & $15.3-23.3$ \\
February & 28 & $15.2-18.5$ & $18.8-23.5$ & 22 & $11.9-18.1$ & $15.3-23.3$ \\
March & 23 & $14.4-19.8$ & $18-25.6$ & 27 & $14.4-20$ & $18-25.7$ \\
April & 24 & $7.2-12.3$ & $9.5-16.4$ & 26 & $6.8-19$ & $8.2-24.5$ \\
May & 20 & $13.4-17.3$ & $17.5-22.5$ & 30 & $13-16.3$ & $16.5-20.5$ \\
June & 23 & $14.6-22$ & $18.5-28$ & 27 & $12.2-18.2$ & $15.5-22.8$ \\
July & 17 & $12.7-18.5$ & $16.2-22.3$ & 33 & $14-16.5$ & $17.5-20.4$ \\
August & 30 & $13.5-17.3$ & $17.5-21.4$ & 20 & $12-17$ & $16.2-21.7$ \\
September & 26 & $11.2-20$ & $14.4-25.3$ & 24 & $13.8-18.8$ & $18-23.7$ \\
October & 29 & $11.5-14.5$ & $13.5-18.2$ & 21 & $10.8-16.2$ & $14-20$ \\
November & 25 & $14.3-18.6$ & $17.2-23.3$ & 25 & $12-18.3$ & $15.5-23$ \\
December & 28 & $12.5-18.3$ & $15.2-22.7$ & 22 & $13.4-17.4$ & $16.7-22.4$ \\
\hline
\end{tabular}

The lowest value of ' $a$ ' was-0.601calculated in December, and the highest 3.951 in August. The minimum value of ' $\mathrm{b}$ ' was 1.01estimated in July, and the maximum 1.325 in April. The generalized relationship of the pooled data over the study period was $\mathrm{TL}=1.214 \mathrm{SL}+0.761$; $\mathrm{R}=0.989$ (Fig. 1). The minimum and maximum correlation coefficients ranged from 0.855 to 0.990, and calculated in February and September respectively. Very high correlation coefficient values indicated a strong association between the two variables in all monthly data. Corollary of monthly growth pattern for the species based on 95\% confidence interval of intercept are documented in Table II. Results showed that growth of $O$. pama in the Bay of Bengal according to SL-TL relationship was allometric in July, August and September, while it was isometric in other months.

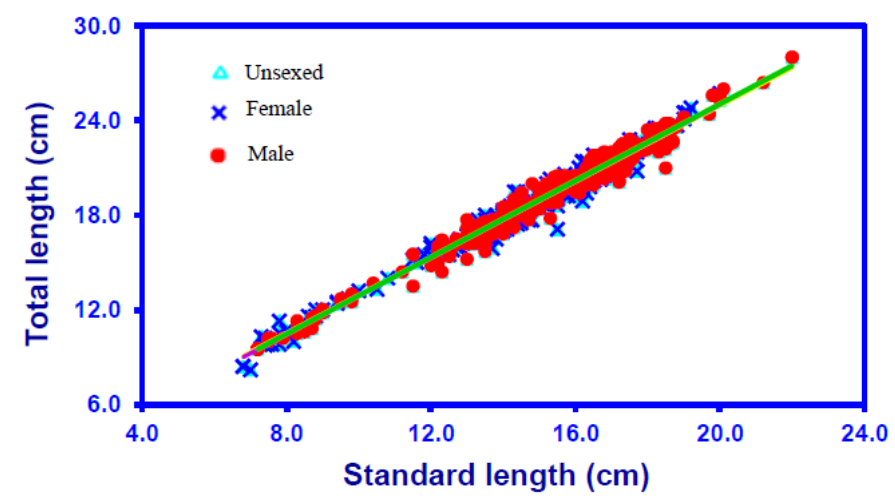

Fig. 1. Generalized relationships between standard length and total length. 
INTERRELATIONSHIP OF LINEAR DIMENSIONS OF PAMA CROAKER

Table II. Parameters of SL vs TL relationships for pama croaker $O$. pama population collected monthly over the study period with growth corollary

\begin{tabular}{|c|c|c|c|c|c|c|c|c|}
\hline Month & Gender & Obs. & $\mathrm{r}$ & $\mathrm{b}$ & $\begin{array}{l}( \pm) \\
\mathrm{Se}_{\mathrm{b}} * \mathrm{t}\end{array}$ & $\mathrm{a}$ & $\begin{array}{l}( \pm) \\
S_{a} * t\end{array}$ & Growth \\
\hline & $\mathrm{M}$ & 27 & 0.933 & 1.158 & 0.014 & 1.813 & 2.811 & Isometric \\
\hline \multirow[t]{2}{*}{ January } & $\mathrm{F}$ & 23 & 0.964 & 1.226 & 0.153 & 0.594 & 2.214 & Isometric \\
\hline & $\mathrm{U}$ & 50 & 0.966 & 1.237 & 0.096 & 0.510 & 1.450 & Isometric \\
\hline \multirow{3}{*}{ February } & $\mathrm{M}$ & 28 & 0.855 & 1.058 & 0.258 & 3.379 & 4.298 & Isometric \\
\hline & $\mathrm{F}$ & 22 & 0.855 & 1.194 & 0.338 & 0.987 & 5.629 & Isometric \\
\hline & $\mathrm{U}$ & 50 & 0.852 & 1.115 & 0.199 & 2.368 & 3.314 & Isometric \\
\hline \multirow{3}{*}{ March } & $\mathrm{M}$ & 23 & 0.970 & 1.301 & 0.148 & -0.495 & 2.438 & Isometric \\
\hline & $\mathrm{F}$ & 37 & 0.971 & 1.312 & 0.133 & -0.713 & 2.219 & Isometric \\
\hline & $\mathrm{U}$ & 50 & 0.971 & 1.307 & 0.094 & -0.608 & 1.557 & Isometric \\
\hline \multirow{3}{*}{ April } & $\mathrm{M}$ & 24 & 0.983 & 1.325 & 0.108 & -0.125 & 0.965 & Isometric \\
\hline & $\mathrm{F}$ & 26 & 0.992 & 1.290 & 0.069 & 0.249 & 0.660 & Isometric \\
\hline & $\mathrm{U}$ & 50 & 0.991 & 1.296 & 0.052 & 0.168 & 0.478 & Isometric \\
\hline \multirow{3}{*}{ May } & $\mathrm{M}$ & 20 & 0.967 & 1.180 & 0.154 & 1.298 & 2.338 & Isometric \\
\hline & $\mathrm{F}$ & 30 & 0.956 & 1.245 & 0.149 & 0.205 & 2.179 & Isometric \\
\hline & $\mathrm{U}$ & 50 & 0.963 & 1.230 & 0.100 & 0.462 & 1.494 & Isometric \\
\hline \multirow{3}{*}{ June } & $\mathrm{M}$ & 23 & 0.967 & 1.192 & 0.120 & 1.197 & 2.133 & Isometric \\
\hline & $\mathrm{F}$ & 27 & 0.980 & 1.155 & 0.097 & 1.662 & 1.533 & Allometric \\
\hline & $\mathrm{U}$ & 50 & 0.983 & 0.032 & 0.065 & 1.069 & 1.085 & Isometric \\
\hline \multirow{3}{*}{ July } & $\mathrm{M}$ & 17 & 0.935 & 1.010 & 0.211 & 3.636 & 3.155 & Allometric \\
\hline & $\mathrm{F}$ & 33 & 0.900 & 1.050 & 0.186 & 3.124 & 2.804 & Allometric \\
\hline & $\mathrm{U}$ & 50 & 0.925 & 1.025 & 0.122 & 3.474 & 1.836 & Allometric \\
\hline \multirow{3}{*}{ August } & $\mathrm{M}$ & 30 & 0.919 & 1.022 & 0.170 & 3.951 & 2.572 & Allometric \\
\hline & $\mathrm{F}$ & 20 & 0.975 & 1.015 & 0.115 & 3.778 & 1.758 & Allometric \\
\hline & $\mathrm{U}$ & 50 & 0.949 & 1.010 & 0.098 & 4.015 & 1.490 & Allometric \\
\hline \multirow{3}{*}{ September } & $\mathrm{M}$ & 26 & 0.990 & 1.149 & 0.068 & 1.863 & 1.103 & Allometric \\
\hline & $\mathrm{F}$ & 24 & 0.930 & 1.024 & 0.179 & 3.894 & 2.887 & Allometric \\
\hline & $\mathrm{U}$ & 50 & 0.977 & 1.121 & 0.071 & 2.328 & 1.145 & Allometric \\
\hline \multirow{3}{*}{ October } & M & 29 & 0.862 & 1.241 & 1.529 & 0.331 & 4.103 & Isometric \\
\hline & $\mathrm{F}$ & 21 & 0.952 & 1.100 & 0.169 & 2.208 & 2.261 & Isometric \\
\hline & $\mathrm{U}$ & 50 & 0.914 & 1.148 & 0.148 & 1.558 & 1.950 & Isometric \\
\hline \multirow{3}{*}{ November } & $\mathrm{M}$ & 25 & 0.960 & 1.251 & 0.156 & -0.293 & 2.586 & Isometric \\
\hline & $\mathrm{F}$ & 25 & 0.981 & 1.220 & 0.105 & 0.412 & 1.627 & Isometric \\
\hline & $\mathrm{U}$ & 50 & 0.974 & 1.204 & 0.082 & 0.563 & 1.313 & Isometric \\
\hline \multirow{3}{*}{ December } & $\mathrm{M}$ & 28 & 0.975 & 1.287 & 0.118 & -0.601 & 1.695 & Isometric \\
\hline & $\mathrm{F}$ & 22 & 0.971 & 1.306 & 2.294 & -0.942 & 2.294 & Isometric \\
\hline & $\mathrm{U}$ & 50 & 0.975 & 1.288 & 0.085 & -0.638 & 1.252 & Isometric \\
\hline
\end{tabular}

Female population: Relationships between standard length vs. total length of monthly samples showed variations in both constants ('a"' and 'b') and correlation coefficients (R) of the linear equations. The lowest value of ' $a$ ' was -0.942 found in December, and the highest 3.894 found in September. The minimum value of ' $b$ ' was 1.015 calculated in July, and the maximum 1.312 
in March (Table II). The generalized relationship of the pooled data over the study period was $\mathrm{TL}=1.212 \mathrm{SL}-0.770 ; \mathrm{R}=0.990$ (Fig. 1). The minimum and maximum correlation coefficients ranged from 0.855 to 0.992 , and were estimated in February and April respectively. Very high correlation coefficient values indicated a strong association between the two variables in all monthly data. Results on of monthly growth pattern showed that growth of $O$. pama in the Bay of Bengal according to SL-TL relationship was allometric in June, July, August and September, while it was isometric in other months (Table II).

Unsexed population: Relationships between standard length and total length of monthly samples showed variations in both constants ('a' and 'b') and correlation coefficients (R) of the linear equations. The lowest value of ' $a$ ' was -0.638 occurred in December, and the highest 4.015 in August. The minimum value of ' $b$ ' was 0.032 computed in June, and the maximum 1.307 in March (Table II). The generalized relationship of the pooled data over the study period was $\mathrm{TL}=1.203 \mathrm{SL}+0.904 ; \mathrm{R}=0.987$ (Fig. 1). The minimum and maximum correlation coefficients ranged from 0.852 to 0.991 , and were calculated in February and April respectively. Very high correlation coefficient values indicated a strong association between the two variables in all monthly data. The growth of $O$. pama in the Bay of Bengal according to SL-TL relationship was allometric in July, August and September, while it was allometric in July, August and September, while it was isometric in other months.

\section{Discussion}

Though works on several aspects of the species fisheries biology as length-frequencies, lengthweight relationships, fish population dynamics, stock assessment, and gear operational system and selectivity of the species are available (Hossain et al. 2015, Hossain et al. 2018, Mustafa et al. 2019, Aung 2018), but studies on construction of length-length relationships, and growth deductions based on interrelationships of linear dimensions were not made before so far our knowledge encompass across literature. Present study recorded total length range of $8.4-28 \mathrm{~cm}$ while Hossain et al. (2015) measured the species TL having a range of $17.4-23.5 \mathrm{~cm}$ in the Tetulia River, southern Bangladesh attributing the reason of large size fish being caught as the result of gear selectivity. Another work undertaken by Bhakta et al. (2019) alluded TL range of O. pama in Hooghly-Matlah estuarine system of West Bengal, India as 10-38.4 cm. Constant and correlation coefficient values, and the growth corollary derived by the present study could not be examined since reference to works alike are absent. The reason, however, why growth pattern happened to be allometric during months over the year in July, August and September would be of immense interest for further investigation. The research was a novel approach to assessing length-length relationships and growth pattern based on them, and the design was, in fact, motivated to cover sampling every month in order to acquire extensive findings to be used as future point of reference.

\section{Literature Cited}

Aung, T.H., 2018. Stock assessment of Otolithoides pama (Hamilton, 1822) in Thanlwin River Mouth, Mon State, Myanmar. J. Aquac. Mar. Biol., 7(4): 241-244. 
Bhakta, D., S.K. Das, B.K. Das, T.S. Nagesh, S. Behera and S.C.S. Das, 2019. Length-weight relationship and condition factor of Otolithoides pama (Hamilton, 1822) from HooghlyMatlah estuarine system of West Bengal, India. Indian J. Fish., 66(4): 51-59

Binohlan, C. and D. Pauly, 2000. The length-weight table. In: Froese R, Pauly D, eds. Fishbase 2000: concepts, design and data sources. ICLARM, Manila, 121-123.

Ecoutin, J.M., J.J. Albaret and S. Trape, 2005. Length-weight relationships for fish populations of a relatively undistributed tropical estuary the Gambia. Fish. Resour., 72: 347-351.

Froese, R. and D. Pauly, 2000. Fishbase: concepts, design and data sources. ICLARM, Manila.

Froese, R., 2006. Cube law, condition factor and weight length relationships: history, metaanalysis and recommendations. J. Appl. Ichthyol., 22: 241-253.

Harrison, T. D., 2001: Length-weight relationships of fishes from South African estuaries. $J$. Appl. Ichthyol., 17: 46-48.

Hossain, M.M., M. Billah, M.B. Hossen and M.H. Rahman, 2018. Operational system and catch composition of charber jal (Fixed Net) in Tetulia River and its impact on fisheries biodiversity in the coastal region of Bangladesh. Nat. Sci., 16(1): 52-61

Hossain, M.Y., S.R.M. Sayed, M.M. Rahman, M.M. Ali, M.A. Hossain, A.M. Elgorban, Z. F. Ahmed and J. Ohtomi, 2015. Length-weight relationships of the nine fishes from the Tetulia River, southern Bangladesh. J. Appl. Ichthyol., 31(5): 967-969.

Martin-Smith, K.M., 1996: Length-weight relationships of fishes in a diverse tropical freshwater community, Sabah, Malaysia. J. Fish Biol., 49: 731-734.

Moutopoulos, D.K. and K.I. Stergiou, 2002. Length-weight and length-length relationships of fish species from Aegean Sea (Greece). J. Appl. Ichthyol., 18: 200-203.

Mustafa, M.G., I. Ahmed and M. Ilyas, 2019. Population dynamics of five important commercial fish species in the Sundarbans ecosystem of Bangladesh. J. Appl. Life Sci, Int., 22(2): 1-13.

Pauly, D., 1993. Fishbyte Section. Editorial. Naga, the ICLARM quarterly, 16-26.

Petrakis, G. and K.I. Stergiou, 1995. Weight-length relationships for 33 fish species in Greek waters. Fish. Res., 21: 465-469. 